\title{
A DETERIORATING FOOD PRESERVATION SUPPLY CHAIN MODEL WITH DOWNSTREAM DELAYED PAYMENT AND UPSTREAM PARTIAL PREPAYMENT
}

\author{
Prasanta Kumar Ghosh ${ }^{1,4}$, Amalesh Kumar Manna ${ }^{2}$, \\ JAYANTA Kumar DEY ${ }^{3}$ AND SAMARJit KAR ${ }^{1, *}$
}

\begin{abstract}
This paper investigates a food supply chain model consisting of the supplier, food producer and multi-retailer of a deteriorating item under fully delay-in-payment and partial advance payment scheme. The deterioration rate of raw material is dependent on temperature and other environmental factors with respect to time. Here, the food producer prepares food after collecting the raw material from the supplier and then storing it in cold storage. The refrigeration cost is dependent on the occupied volume in the cold storage (where the products are preserved for freshness) and power consumption. The supplier offers delay-in-payment to stimulate the food producer to buy more raw material (which minimizes the holding cost and earns more revenues), whereas the food producer takes the partial advance payment on purchase cost from the retailers to ensure the order quantity. A mathematical model is developed to obtain optimal production time and the optimal number of deliveries so that the average profit of the food producer is maximum. Finally, a numerical example and sensitivity analysis of the key parameters are provided to illustrate and test the feasibility of the proposed model.
\end{abstract}

Mathematics Subject Classification. 90B05, 90B15, 90B25, 90B30, $90 \mathrm{~B} 50$.

Received October 23, 2019. Accepted November 21, 2021.

\section{INTRODUCTION}

In this world, food deterioration is a common phenomenon in developing countries and may cause economic loss. In many countries, food supply chain management affronts a huge challenge of food quality, food safety, public health, demand, price variability and weather-related variability etc. On the other hand, perishable products are important in inventory management because customers strive for quality. According to Ferguson and Katzenberg [11], 15\% (approximately) of foods deteriorates in the food retailing sector. Also, more than $25 \%$ of fruit and vegetables are deteriorated in China during transportation, at wholesale markets and in shops (cf. [22]). Food products are the most delicate goods on the market due to insufficient storage, the wrong

Keywords. Supply chain, deteriorating items, delay-in-payment, advance payment.

1 Department of Mathematics, National Institute of Technology Durgapur, Durgapur 713209, India.

2 Department of Mathematics, The University of Burdwan, Burdwan 713104, India.

3 Department of Mathematics, Mahisadal Raj College, Mahisadal 721628, India.

4 Department of Mathematics, Y.S. Palpara Mahavidyalaya, Purba Midnapore 721458, India.

*Corresponding author: kar_s_k@yahoo.com 
temperature levels, lower air quality, the risk of humidity, light and other factors affecting quality and safety. Examples of this are to ensure: without any optimum temperature, bacteria increases uncontrollably and light directly affects the quality of a new product [29]. Similarly, without proper storage, the product became destructive. Therefore, every storage room should be equipped with a control unit to report temperature levels at any time. Food security aims to protect health and securing the free flow of food to the market [25]. Food companies dealing with food have two parallel systems for food quality preservation and safety [23].

Several researchers proposed various types of preservation investment in the business world. To reduce the deterioration in an inventory system, preservation technology investment is the best policy ( $c f$. [10]). Also, Dye and Hsieh [10] analyse the strategies of preservation technology investment on the optimal order quantity, which maximizes the average profit over the infinite time horizon. Preservation technology investment plays an important role to maintain the the freshness of the perishable products. Chen and Dye [4] investigate an inventory problem under preservation technology investment over a finite time horizon and show that investment is different for each replenishment cycle. Considering a deterioration inventory problem, He and Huang [17] determine the optimal preservation technology investment and pricing of the product. The deterioration rate of the products in an inventory model can be expressed by the Weibull function (cf. [28]), whereas the demand rate is increases with time [1,27]. Recently, Das et al. [7] analyse the effect of trade credit financing by considering preservation investment in a non-instantaneous deteriorating inventory model. Several researchers like Corradini and Peleg [6], Qin and Wei [24], Corradini and Peleg [37], and others developed different models based on temperature dependent deterioration rates for the perishable product.

A good number of inventory models are proposed based on the assumptions that payment is made at the time of order quantity received. But, real situations are different about the payment of purchasing cost: (i) payment on delivery received ([21] and others), (ii) permissible partial delay-in-payment ([2,14] and others) (iii) partial advance payment ([30] and others), and (iv) partial advance payment and permissible partial delay-in-payment [12]. Goyal [14] is the first and pioneer researcher who considered delay-in-payment in an inventory model. Thangam and Uthayakumar [34] presents a bi-level trade credit scheme based supply chain model with credit period and selling price dependent market demand. Considering the two-level trade credit scheme, an integrated inventory model was developed by Chen and Kang [5]. An inventory model with non-decreasing linear demand function and trade credit policy is formulated by Teng et al. [32]. Mahata [20] explains a partial trade credit facility based supply chain model for deteriorating items. A production inventory model under trade credit financing and maintenance of the manufacturing system was developed by Tsao [36]. Incorporating the bi-level trade credit facility in an inventory problem with partial backlogged shortages, Tiwari et al. [35] determine the optimal selling price and replenishment cycle time for maximizing the average profit. Taking time-varying deterioration rate and permissible delay-in-payment policy, a two-warehouse inventory model was developed by Gupta et al. [15].

For controlling the cash flow of the supply chain model, the advance payment scheme is one of the most untroubled and without default risk. The advance payment scheme suggested by the manufacturer is the monopolistic concept in a business environment. For riskless and secure business, sometimes the upstream traders (suppliers, manufacturers, retailers) offer quantity discounts, price discounts, free shipping, etc., to the downstream buyers for full or partial advance payment. Several researchers established and analyzed the advance payment policy in the inventory model since the advance payment assures the production/inventory management for sure exhaustiveness of quantity. According to Zhang [38], advance payment policy is used when the purchasing cost of the product is more than the billed amount. Later, considering multiple advanced payment policy, an inventory model with partial backlogged shortages for deteriorating items was developed by Taleizadeh [31]. Teng et al. [33] considered an inventory problem with an advance payment policy for deteriorating items with expiration dates. An advance payment scheme in a two-warehouse inventory model for deteriorating items with partial backlogging is studied by Khan et al. [18]. Ghosh et al. [12] developed a single manufacturer and multi-retailer supply chain model under advanced payment and delay-in-payment scheme. In Table 1, a compact illustration of the literature review related to the proposed model is described. 
TABLE 1. Comparison table, based on various assumptions related to the propose problem.

\begin{tabular}{|c|c|c|c|c|c|}
\hline Author(s) & $\begin{array}{l}\text { Deteriorating } \\
\text { products model }\end{array}$ & $\begin{array}{l}\text { Deterioration } \\
\text { dependent on }\end{array}$ & $\begin{array}{l}\text { Cold storage/ } \\
\text { preservation } \\
\text { facility }\end{array}$ & $\begin{array}{l}\text { Delay-in-payment } \\
\text { scheme }\end{array}$ & $\begin{array}{l}\text { Prepayment } \\
\text { scheme }\end{array}$ \\
\hline $\begin{array}{l}\text { Bhunia and } \\
\text { Shaikh [2] }\end{array}$ & $\sqrt{ }$ & Constant & $x$ & $\sqrt{ }$ & $x$ \\
\hline $\begin{array}{l}\text { Chen and Dye } \\
{[4]}\end{array}$ & $\sqrt{ }$ & Constant & $\sqrt{ }$ & $x$ & $x$ \\
\hline $\begin{array}{l}\text { Diabat et al. } \\
{[8]}\end{array}$ & $\sqrt{ }$ & Constant & $\times$ & $\sqrt{ }$ & $\sqrt{ }$ \\
\hline $\begin{array}{l}\text { Dye and } \\
\text { Hsieh [10] }\end{array}$ & $\sqrt{ }$ & Constant & $\sqrt{ }$ & $x$ & $x$ \\
\hline Dye [9] & $\sqrt{ }$ & Time & $\sqrt{ }$ & $x$ & $x$ \\
\hline $\begin{array}{l}\text { He and Huang } \\
{[17]}\end{array}$ & $\sqrt{ }$ & $\begin{array}{l}\text { Technology } \\
\text { ivestment }\end{array}$ & $\sqrt{ }$ & $x$ & $x$ \\
\hline $\begin{array}{l}\text { Khan et al. } \\
{[18]}\end{array}$ & $\sqrt{ }$ & Constant & $x$ & $x$ & $\sqrt{ }$ \\
\hline Li et al. [19] & $\sqrt{ }$ & Constant & $x$ & $x$ & $\sqrt{ }$ \\
\hline $\begin{array}{l}\text { Skouri et al. } \\
{[28]}\end{array}$ & $\sqrt{ }$ & $\begin{array}{l}\text { Weibull } \\
\text { deterioration }\end{array}$ & $\times$ & $x$ & $x$ \\
\hline $\begin{array}{l}\text { Shah et al. } \\
{[26]}\end{array}$ & $x$ & $x$ & $x$ & $\sqrt{ }$ & $\sqrt{ }$ \\
\hline $\begin{array}{l}\text { Taleizadeh } \\
\text { et al. [30] }\end{array}$ & $x$ & $x$ & $\times$ & $x$ & $\sqrt{ }$ \\
\hline $\begin{array}{l}\text { Taleizadeh } \\
{[31]}\end{array}$ & $\sqrt{ }$ & Constant & $\times$ & $x$ & $\sqrt{ }$ \\
\hline $\begin{array}{l}\text { Teng et al. } \\
\text { [33] }\end{array}$ & $\sqrt{ }$ & Time & $\times$ & $\times$ & $\sqrt{ }$ \\
\hline Zhang [38] & $x$ & $x$ & $x$ & $x$ & $\sqrt{ }$ \\
\hline Present paper & $\sqrt{ }$ & $\sqrt{ }$ & $\sqrt{ }$ & $\sqrt{ }$ & $\sqrt{ }$ \\
\hline
\end{tabular}

Sometimes, a part of the purchase cost paid before the delivery and the rest portion of the requisition cost is paid as on the delivery. This type of payment policy is known as the advance-cash-credit (ACC) policy. Diabat et al. [8] developed a lot-sizing model with partial backorder for deteriorating items under partial downstream delay-in-payment and partial upstream advance payment. In the same year, Li et al. [19] analyzed the pricing and lot-sizing policies for time-dependent deteriorating products under the advance-cash-credit(ACC) policy. After that, Shah et al. [26] determined the optimal replenishment time under partial upstream prepayment and partial downstream overdue payment for quadratic demand. Recently, Ghosh et al. [12] introduced the concept of advance and delayed payments policies for financially strong and week retailers in a green supply chain model. Ghosh et al. [13] also proposed the joint effect of advance and delayed payments policies in an inventory problem for perishable goods.

In this study, a food preservation supply chain model is formulated under upstream partial advance payment and downstream delay-in-payment policy. Food deterioration rate before preservation is dependent on environmental factors and temperature with respect to time. The cold storage cost of processing food depends on the volume (space) of cold storage and power consumption. Here, two types of holding costs, such as the holding cost of raw material, stocks in normal temperature and cold storage cost of prepared food, which depends on volume (space) of cold storage and power consumption, are considered. Also, the food producer gets joint benefit by delay-in-payment as well as advanced payment schemes from supplier and retailers, respectively. Finally, the 


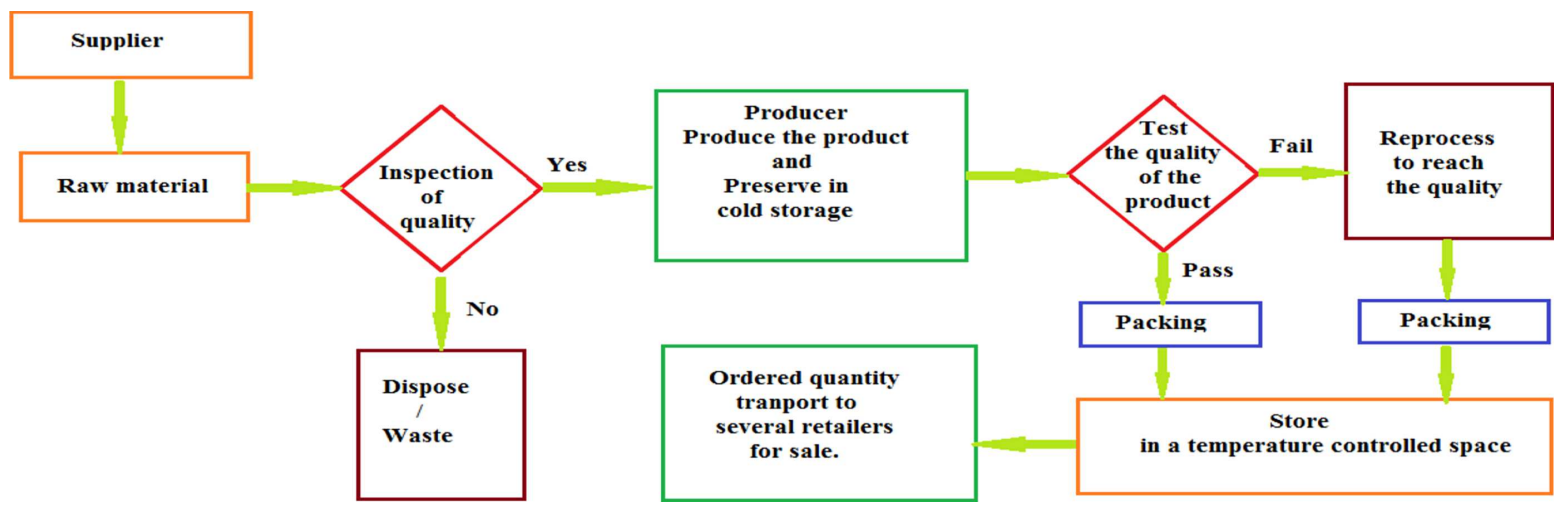

FiguRE 1. Schematic diagram of the supply chain model.

main objective is to maximize the average profit of the food producer through the coordination of the members of the supply chain system.

The remainder of the paper is organized as follows: Section 2 presents the problem description of the proposed model. Section 3 develops the mathematical formulation of the proposed model. Theoretical results for the optimum solutions related to the proposed model provides in Section 4. The solution procedure of the optimization problem is given in Section 5. A numerical example and sensitivity analysis are presented in Sections 6 and 7 , respectively. The managerial insights are discussed in Section 8. Finally, Section 9 provides a fruitful conclusion with future research directions of this study.

\section{Problem DESCRIPTION}

In the beginning, the food producer receives the raw material from the supplier. Due to the deterioration effect, the food producer inspects the raw material and produces food from fresh items. The produced food is preserved in the preservation centre and delivered to the retailers. The schematic diagram of the proposed model is shown in Figure 1.

The following assumptions and notation are used while developing this proposed supply chain model mathematically.

\subsection{Assumptions}

(i) A food supply chain model with advanced and delayed payments is formulated. The supply chain network consists of the supplier, food producer and multiple retailers. At first, the supplier collects the raw materials (fruits, vegetables, etc.) from the farmer and supplies them to the food producer. Retailers receive the products in bulk from food producer to meet up the market demand.

(ii) The deterioration rate of raw material depends on the environmental parameters and temperature with respect to time. The mathematical form of the deterioration rate is $\theta(t)=\alpha \beta t^{\beta-1}$ where $\alpha>0$ and $\beta>0$ are respectively, the environmental factors and temperature coefficients depend on time $t$.

(iii) The unit food preparation cost is considered as constant.

(iv) Here, two types of holding cost are considered: (a) the holding cost $\left(h_{c}\right)$ of raw material in $i$ th cycle which stock in normal temperature, (b) cold storage cost $\left(c_{s}\right)$ of packet food in $i$ th cycle which store in a temperature controlled area. Cold storage cost depends on the volume (space) of cold storage (where the products are preserved for freshness) and power consumption. The nature of the holding cost is cumulative on time based on how many units of the finished product is stored and how much time it is preserved. The potential function is $\phi(x, t)=c_{s} x e^{\nu t}$, where $c_{s}$ and $\nu$ (power consumption coefficient) are both positive 
constant. For preservation, $\phi(1,1)=c_{s} e^{\nu}>0$ represents the holding cost of one unit of the finished product for one unit of time. Obviously, $\phi(I, u)>\phi(1,0)$ for $I>1$ and $u>0$.

(v) The supplier offers the producer a fully delay-in-payment of period $T$ from the quantity received. Due to delay-in-payment of the period $T$, the producer earned interest with the rate $i_{e}$ on the purchasing cost of the raw material quantity $Q_{s i}$.

(vi) The food producer receives the advance payment from the retailers as partial payment in $\left(k_{j}-1\right)$ equal shipment from the $j$ th retailers for the delivery of quantity $Q_{m j}$ and the remaining part is received in the time of delivery at $k_{j}$ th installment. So, the food producer get interest from a partial advance payment scheme.

\subsection{Notation}

\begin{tabular}{|c|c|c|}
\hline $\begin{array}{l}\text { Decision } \\
\text { variables }\end{array}$ & : & Description \\
\hline$T$ & : & Time length of the total production in a cycle \\
\hline$n$ & : & Number of the delivered cycle of raw material by the supplier to the food producer \\
\hline $\begin{array}{l}\text { Related to } \\
\text { the decision } \\
\text { variables }\end{array}$ & : & Description \\
\hline$Q_{s i}$ & : & The order quantity of food producer to the supplier for $i$ th cycle \\
\hline$Q_{s}$ & : & Total order quantity \\
\hline Parameter & : & Description \\
\hline$I_{m}(t)$ & : & Inventory level at any time $t$ of the raw material of food producer \\
\hline$\theta$ & : & Deterioration rate of raw material \\
\hline$m$ & : & Number of delivered cycles after the end of the food preparation \\
\hline$c_{i}$ & : & Raw material inspection cost per unit \\
\hline$c_{h}$ & : & Holding cost per unit of raw material per unit of time \\
\hline$c_{s}$ & : & Cold storage cost per unit of product (food) per unit of time \\
\hline$s$ & : & The selling price of the product per unit \\
\hline$\lambda(>1)$ & : & Amount of raw material to produce one unit of product \\
\hline$p$ & : & Food preservation rate in a cold storage \\
\hline$c_{p}$ & : & Manufacture's unit purchase cost of the product \\
\hline$c_{f p}$ & : & Unit preparation cost of the food \\
\hline$r$ & : & Number of retailers \\
\hline$i_{e}$ & : & Interest earned in unit per year due to delay-in-payment policy \\
\hline$i_{e}^{d}$ & : & Interest earned in unit per year due to advance payment policy \\
\hline$Q_{m}$ & : & Delivered quantity of producer in each cycle to the retailers, where $Q_{m}=\sum_{j=1}^{r} Q_{m j}$ \\
\hline$Q_{m j}$ & & Demand quantity of $j$ th retailer s.t. $Q_{m j}=\delta_{j} Q_{m}$ where $0 \leq \delta_{j} \leq 1$ and $\sum_{j=1}^{r} \delta_{j}=1$ \\
\hline$K$ & : & Fixed ordering cost for each order \\
\hline$c_{t 0}, c_{t 1}$ & : & $\begin{array}{l}\text { Transportation cost }\left(c_{t 0}>0\right) \text { fixed for each delivers and } c_{t 1}>0 \text { cost coefficient } \\
\text { depends on per quantity delivered }\end{array}$ \\
\hline$\alpha, \beta$ & $:$ & Temperature-dependent coefficients which are both positive \\
\hline & : & Power consumption coefficient which is positive \\
\hline$T^{*}, n^{*}$ & : & The optimum values of decision variables \\
\hline
\end{tabular}

\section{Mathematical Description of The MOdeL}

The inventory levels of the supplier, food producer with the preservation and delivered to the retailers are shown in Figure 2. Considering $T$ is the total time for food preparation with preservation and divided by $n$ equal spacing time zone. The $i$ th cycle of food prepared and preservation is $\left[(i-1) \frac{T}{n}, i \frac{T}{n}\right]$ for $i=1,2, \ldots, n$. At the beginning of $i$ th cycle, the food producer receives an order $Q_{s i}$ quantity of raw material from the supplier. After receiving the raw material, an inspection (screening) is done with the rate $\lambda p$ before it is sent to the food preparation. Due to the deterioration of raw material, some portions of raw materials are rejected. After 


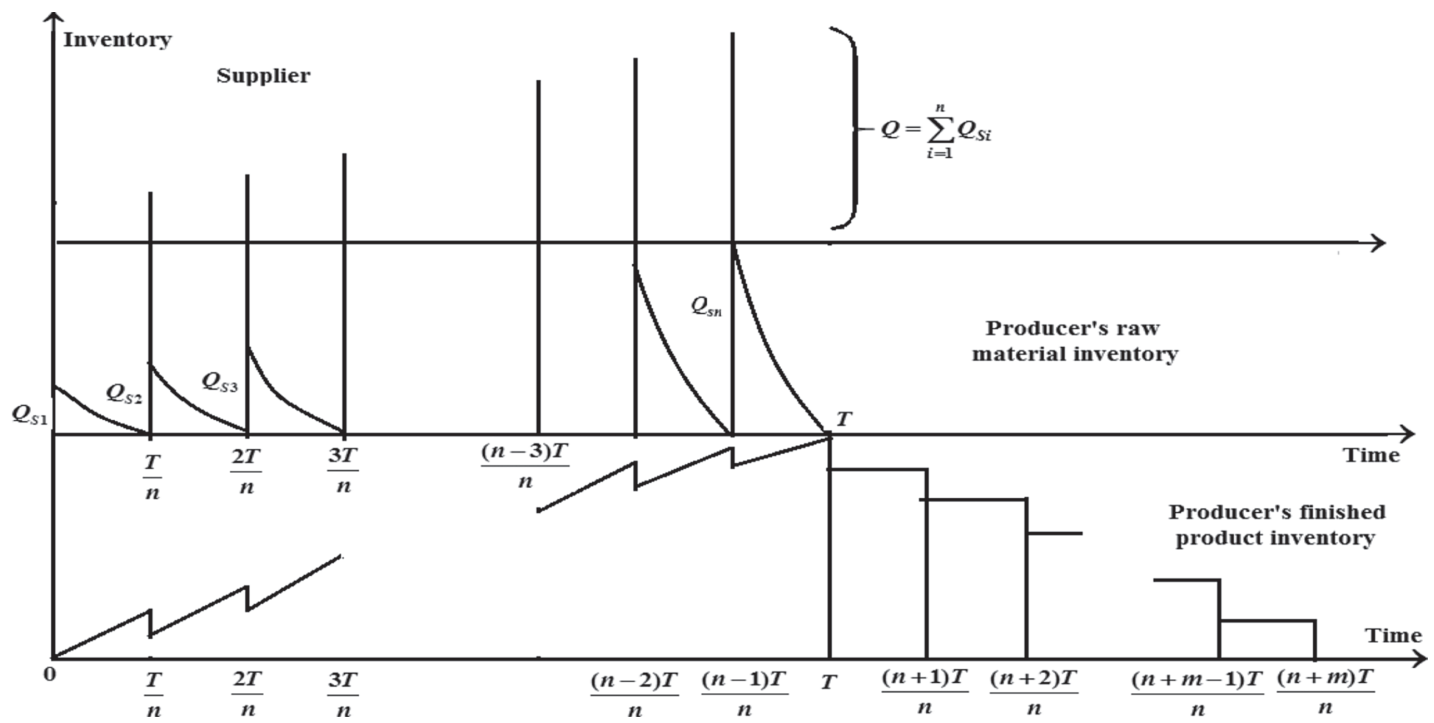

FiguRE 2. Graphical representation of supplier, producer and retailers inventory system.

that, the fresh raw materials are used to prepare the food with a rate $p$ in the food producer and preserved for delivery to the retailers. The quality control team check the level of quality of the prepared food. If the items are passed through the inspection process, then the stored product in temperature controlled storage are wait until the container trucks arrive to transport them to the retailers. If the quality level of prepared product (food) does not reach its optimum quality level, then reprocess it.

Due to the deterioration (which depends on environmental factors and temperature coefficient with respect to time) of raw materials, the order quantity of raw materials increases with time. So, $Q_{s i}$ increases with time for $i=1,2,3, \ldots, n$. The deterioration rate $\theta(t)=\alpha \beta t^{\beta-1}$, where $\alpha>0$ and $\beta>0$ are the environmental parameters and temperature coefficients depend on time $t$. To produce $p$ unit of the finished product (food) per unit time, the system needs $\lambda p$ unit of raw material per unit time. The inventory level of raw material at time $t$ decreases due to the inspection (screening) with a rate $\lambda p$ and immediately prepare the product (food) with a rate $p$ at the production centre of the food producer. Accordingly, under this description, the rate of changes in the inventory of raw material can be described using the following differential equation.

$$
\frac{\mathrm{d} I_{m}(t)}{\mathrm{d} t}=-\lambda p-\alpha \beta t^{\beta-1} I_{m}(t), \quad \text { in } \quad \frac{(i-1) T}{n} \leq t \leq \frac{i T}{n}
$$

with the condition $I_{m}\left(\frac{i T}{n}\right)=0$ for $i=1,2,3, \ldots, n$.

Solving the equation (3.1) with approximation, the following relation is obtained

$$
I_{m}(t)=\lambda p\left[\frac{i T}{n}-t+\frac{\alpha}{\beta+1}\left[\left(\frac{i T}{n}\right)^{\beta+1}-t^{\beta+1}\right]\right], \quad \text { in } \quad \frac{(i-1) T}{n} \leq t \leq \frac{i T}{n}, i=1,2, \ldots, n .
$$

Under the initial condition $I_{m}\left(\frac{(i-1) T}{n}\right)=Q_{s i}, i=1,2, \ldots, n$, the following relation is obtained

$$
Q_{s i}=\lambda p\left(\frac{T}{n}+\frac{\alpha}{\beta+1}\left(\frac{T}{n}\right)^{\beta+1}\left[i^{\beta+1}-(i-1)^{\beta+1}\right]\right) .
$$

The food producer order $Q_{s i}$ units of $i$ th cycle is different and increase with the cause of increasing deterioration with respect to increasing of time. Now different costs associated with this proposed model are as follows: 
Food producer's raw material purchasing cost (RMPC) is given by

$$
\mathrm{RMPC}=c_{p} \sum_{i=1}^{n} Q_{s i}=\lambda p c_{p}\left(T+\frac{\alpha}{\beta+1} T^{\beta+1}\right) .
$$

Food producer's raw material inspection cost (RMIC) is given by

$$
\mathrm{RMIC}=c_{i} \sum_{i=1}^{n} Q_{s i}=\lambda p c_{i}\left(T+\frac{\alpha}{\beta+1} T^{\beta+1}\right) .
$$

Food producer's finished product (food) preparation cost (MFPC) is given by

$$
\mathrm{MFPC}=c_{f p} p T
$$

Food producer's holding cost of raw material for $i$ th cycle in $\left[\frac{(i-1) T}{n}, \frac{i T}{n}\right]$ is given by

$$
\mathrm{IH}_{i}=\int_{\frac{(i-1) T}{n}}^{\frac{i T}{n}} I_{m}(t) \mathrm{d} t=\lambda p\left(\frac{T^{2}}{2 n^{2}}+\frac{\alpha \beta}{(\beta+1)(\beta+2)} \frac{T^{\beta+2}}{n^{\beta+2}}\left[i^{\beta+2}-(i-1)^{\beta+2}\right]\right) .
$$

The total holding cost (THC) of the food producer during $[0, T]$ is given by

$$
\mathrm{THC}=c_{h} \sum_{i=1}^{n} \mathrm{IH}_{i}=c_{h} \lambda p\left(\frac{T^{2}}{2 n}+\frac{\alpha \beta}{(\beta+1)(\beta+2)} T^{\beta+2}\right) .
$$

Cold storage cost depends on the volume (space) of cold storage (where the products are preserved for freshness) and power consumption. The nature of the holding cost is cumulative on time based on how many units of the finished product is stored and how much time it is preserved. The potential function is $\phi(x, t)=c_{s} x e^{\nu t}$, where $c_{s}$ and $\nu$ (power consumption coefficient) are both positive constant. For preservation, $\phi(1,1)=c_{s} e^{\nu}>0$ represents the holding cost of one unit of the finished product for one unit of time. Obviously, $\phi(I, u)>\phi(1,0)$ for $I>1$ and $u>0$.

The total cold storage cost (TCSC) is given by

$$
\begin{aligned}
\operatorname{TCSC} & =c_{s} \int_{0}^{T} p t e^{\nu t} \mathrm{~d} t \\
& =c_{s} \sum_{i=1}^{n}(i-1) Q_{m} \int_{\frac{(i-1) T}{n}}^{\frac{i T}{n}} e^{\nu t} \mathrm{~d} t+c_{s} \sum_{j=0}^{m-1}(m-j) Q_{m} \int_{\frac{(n+j) T}{n}}^{\frac{(n+j+1) T}{n}} e^{\nu t} \mathrm{~d} t \\
& =\frac{c_{s} p}{\nu^{2}}\left[1-e^{\nu T}+\nu T e^{\nu T}\right]+\frac{c_{s} Q_{m}}{\nu}\left[\frac{\left(e^{\frac{(n+m+1) \nu T}{n}}-e^{\frac{\nu T}{n}}\right)+(n+m)\left(e^{\nu T}-e^{\frac{(n+1) \nu T}{n}}\right)}{\left(e^{\frac{\nu T}{n}}-1\right)}\right] .
\end{aligned}
$$

The ordering and transportation cost $(O C T C)$ is given by

$$
\mathrm{OCTC}=n K+\sum_{i=1}^{n}\left(c_{t 0}+c_{t 1} Q_{s i}\right)=n\left(K+c_{t 0}\right)+c_{t 1} \lambda p\left(T+\frac{\alpha}{\beta+1} T^{\beta+1}\right) .
$$

Therefore the total cost involving in the supply chain is

$$
\Psi_{\mathrm{TC}}(T, n)=n\left(K+c_{t 0}\right)+c_{f p} p T+\left(c_{p}+c_{i}+c_{t 1}\right) \lambda p\left(T+\frac{\alpha}{\beta+1} T^{\beta+1}\right)
$$




$$
\begin{aligned}
& +c_{h} \lambda p\left(\frac{T^{2}}{2 n}+\frac{\alpha \beta}{(\beta+1)(\beta+2)} T^{\beta+2}\right)+\frac{c_{s} p}{\nu^{2}}\left[1-e^{\nu T}+\nu T e^{\nu T}\right] \\
& +\frac{c_{s} Q_{m}}{\nu}\left[\frac{\left(e^{\frac{(n+m+1) \nu T}{n}}-e^{\frac{\nu T}{n}}\right)+(n+m)\left(e^{\nu T}-e^{\frac{(n+1) \nu T}{n}}\right)}{\left(e^{\frac{\nu T}{n}}-1\right)}\right]
\end{aligned}
$$

Lemma 3.1. In the food production system, dispatch quantity must satisfy the following relation in terms of the production rate with production time, which is $(n+m) Q_{m}=p T$.

Proof. The rate of producing the item of the food producer is $p$ during the period $[0, T]$. On the other hand, the food producer sells lot size $Q_{m}$ in each cycle. The total number of the shipment to the retailer is $(n+m)$. Therefore, $p T=(n+m) Q_{m}$. Hence the proof is complete.

Total sales revenue (TSR) for the food producer during the period $\left[0, \frac{(n+m) T}{n}\right]$ is given by

$$
\mathrm{TSR}=\sum_{i=1}^{n+m} s Q_{m}=s p T .
$$

Opportunity cost by the supplier is the revenue earn an interest of the food producer for the delay-in-payment policy (MIEDP) is given by

$$
\mathrm{MIEDP}=\sum_{i=1}^{n} c_{p} i_{e} Q_{s i} \frac{T}{n}=\frac{c_{p} i_{e} \lambda p}{n}\left(T^{2}+\frac{\alpha}{\beta+1} T^{\beta+2}\right) .
$$

The food producer receives the advance payment from the retailers as partial payment in $\left(k_{j}-1\right)$ equal shipment from the $j$ th retailers for the delivery of quantity $Q_{m j}$ and the remaining part is received in the time of delivery at $k_{j}$ th installment. So, interest will be gain by the food producer for partial advance payment.

Food producer's interest earn as gain in the $i$ th cycle from the $j$ th retailers (MIEJ) is given by

$$
\text { MIEJ }=i_{e}^{d} s \beta_{j} \frac{Q_{m j}}{k_{j}}\left(1+2+3+\ldots+\left(k_{j}-1\right)\right) \frac{T}{n k_{j}}=s i_{e}^{d} \beta_{j} \frac{\left(k_{j}-1\right)}{2 k_{j}} Q_{m j} \frac{T}{n} .
$$

Let, $Q_{m j}=\delta_{j} Q_{m}$ for $j=1,2, \ldots, r$ and $0 \leq \delta_{j} \leq 1$, so that $\sum_{j=1}^{r} \delta_{j}=1$, then $\sum_{j=1}^{r} Q_{m j}=Q_{m}$. In this aspect, food producer's interest earn as gain in the $i$ th cycle from all the retailers (MIEI) is given by

$$
\begin{gathered}
\text { MIEI }=i_{e}^{d} s \frac{T}{n} \sum_{j=1}^{r} \beta_{j} Q_{m j} \frac{k_{j}-1}{2 k_{j}}=i_{e}^{d} s Q_{m} \Delta_{i} \frac{T}{n}, \\
\text { where, } \Delta_{i}=\sum_{j=1}^{r} \beta_{j} \delta_{j} \frac{k_{j}-1}{2 k_{j}}, \quad \text { for } i=1,2, \ldots,(n+m) .
\end{gathered}
$$

Hence, food producer's total interest earn due to advance payment from the retailers (MTIEA) is given by

$$
\text { MTIEA }=\sum_{i=1}^{n+m} i_{e}^{d} s Q_{m} \frac{T}{n} \Delta_{i}=i_{e}^{d} s Q_{m} \frac{T}{n} \eta, \quad \text { where } \eta=\sum_{i=1}^{n+m} \Delta_{i} .
$$

Now, the total revenue for selling of product and interest earned for advance payment by retailers and interest earned for the delay-in-payment in the supply chain $\left(\Psi_{\mathrm{SR}}(T, n)\right)$ is given by

$$
\Psi_{\mathrm{SR}}(T, n)=s p T+i_{e}^{d} s Q_{m} \frac{T}{n} \eta+\frac{c_{p} i_{e} \lambda p}{n}\left(T^{2}+\frac{\alpha}{\beta+1} T^{\beta+2}\right) .
$$


The total profit in the supply chain is $\Psi_{\mathrm{PROFIT}}(T, n)=\Psi_{\mathrm{SR}}(T, n)-\Psi_{\mathrm{TC}}(T, n)$. So, the profit per unit time is

$$
\begin{aligned}
\Pi_{m}(T, n)= & \frac{n}{(n+m) T}\left(\left[s p T+i_{e}^{d} s Q_{m} \frac{T}{n} \eta+\frac{c_{p} i_{e} \lambda p}{n}\left(T^{2}+\frac{\alpha}{\beta+1} T^{\beta+2}\right)\right]\right. \\
& -\left[n\left(K+c_{t 0}\right)+c_{f p} p T+\left(c_{p}+c_{i}+c_{t 1}\right) \lambda p\left(T+\frac{\alpha}{\beta+1} T^{\beta+1}\right)\right. \\
& +c_{h} \lambda p\left(\frac{T^{2}}{2 n}+\frac{\alpha \beta}{(\beta+1)(\beta+2)} T^{\beta+2}\right)+\frac{c_{s} p}{\nu^{2}}\left[1-e^{\nu T}+\nu T e^{\nu T}\right] \\
& \left.\left.+\frac{c_{s} Q_{m}}{\nu}\left[\frac{\left(e^{\frac{(n+m+1) \nu T}{n}}-e^{\frac{\nu T}{n}}\right)+(n+m)\left(e^{\nu T}-e^{\frac{(n+1) \nu T}{n}}\right)}{\left(e^{\frac{\nu T}{n}}-1\right)}\right]\right]\right) .
\end{aligned}
$$

From the result of Lemma 3.1, $Q_{m}=\frac{p T}{(n+m)}$ and using in (3.19), the objective function becomes

$$
\begin{aligned}
\Pi_{m}(T, n)= & \frac{n}{(n+m) T}\left(\left[s p T+i_{e}^{d} s p \frac{T^{2}}{n(n+m)} \eta+\frac{c_{p} i_{e} \lambda p}{n}\left(T^{2}+\frac{\alpha}{\beta+1} T^{\beta+2}\right)\right]\right. \\
& -\left[n\left(K+c_{t 0}\right)+c_{f p} p T+\left(c_{p}+c_{i}+c_{t 1}\right) \lambda p\left(T+\frac{\alpha}{\beta+1} T^{\beta+1}\right)\right. \\
& +c_{h} \lambda p\left(\frac{T^{2}}{2 n}+\frac{\alpha \beta}{(\beta+1)(\beta+2)} T^{\beta+2}\right)+\frac{c_{s} p}{\nu^{2}}\left[1-e^{\nu T}+\nu T e^{\nu T}\right] \\
& \left.\left.+\frac{c_{s} p T}{\nu(n+m)}\left[\frac{\left(e^{\frac{(n+m+1) \nu T}{n}}-e^{\frac{\nu T}{n}}\right)+(n+m)\left(e^{\nu T}-e^{\frac{(n+1) \nu T}{n}}\right)}{\left(e^{\frac{\nu T}{n}}-1\right)}\right]\right]\right)
\end{aligned}
$$

subject to $T \geq 0$ and $n \in Z^{+}$(positive integer set).

\section{TheORETICAL RESUlTS OF OPTIMUM POLICY}

Our objective is to maximize the profit per unit time of the proposed inventory model with the optimum values of $T$ and $n$. By considering the first order derivatives of $\Pi_{m}(T, n)$ with respect to $T$ and $n$ and setting to zero, gives $\frac{\partial \Pi_{m}(T, n)}{\partial T}=0$ and $\frac{\partial \Pi_{m}(T, n)}{\partial n}=0$.

To avoid complexity, it can be solved for a particular value of $\beta$ and obtained the optimum solution as $T=T^{*}$ and $n=n^{*}$, which maximizes globally and unique to the objective shown in Appendix A. By the approximation of Taylor's series expansion, we obtain

$$
\frac{\left(e^{\frac{(n+m+1) \nu T}{n}}-e^{\frac{\nu T}{n}}\right)+(n+m)\left(e^{\nu T}-e^{\frac{(n+1) \nu T}{n}}\right)}{\left(e^{\frac{\nu T}{n}}-1\right)}=\frac{1}{2}(n+m)(m+1-n)\left(\frac{\nu T}{n}-\frac{\nu^{2} T^{2}}{2 n^{2}}\right) .
$$

Then

$$
\begin{aligned}
\Pi_{m}(T, n)= & \frac{1}{T}\left[\frac{\alpha p \lambda}{(n+m)(\beta+1)}\left(c_{p} i_{e}-\frac{n \beta c_{h}}{\beta+2}\right) T^{\beta+2}-\frac{n \alpha p \lambda}{(n+m)(\beta+1)}\left(c_{p}+c_{i}+c_{t 1}\right) T^{\beta+1}\right. \\
& -\frac{c_{s} \nu(n-m-1) p}{4 n(n+m)} T^{3}+\left(c_{p} \lambda i_{e} p+\frac{s i_{e}^{d} p \eta}{n+m}+\frac{c_{s} p(n-m-1)}{2}-\frac{c_{h} \lambda p}{2}\right) \frac{T^{2}}{(n+m)}
\end{aligned}
$$




$$
\left.+\frac{n p}{(n+m)}\left(s-c_{f p}-\lambda c_{p}-\lambda c_{i}-\lambda c_{t 1}\right) T-\frac{n^{2}}{(n+m)}\left(K+c_{t 0}\right)\right]
$$

For the given values of $n$, one has $\Pi_{m}(T, n)=\frac{\Pi_{m 1}(T)}{\Pi_{m 2}(T)}$, where $\Pi_{m 2}(T)=T>0$ for all $T \in(0, \infty)$. Again $\frac{\mathrm{d} \Pi_{m 2}(T)}{\mathrm{d} T}=1>0$ for all $T$ and

$$
\begin{aligned}
\Pi_{m 1}(T)= & \frac{\alpha p \lambda}{(n+m)(\beta+1)}\left(c_{p} i_{e}-\frac{n \beta c_{h}}{\beta+2}\right) T^{\beta+2}-\frac{n \alpha p \lambda}{(n+m)(\beta+1)}\left(c_{p}+c_{i}+c_{t 1}\right) T^{\beta+1} \\
& -\frac{c_{s} \nu(n-m-1) p}{4 n(n+m)} T^{3}+\left(c_{p} \lambda i_{e} p+\frac{s i_{e}^{d} p \eta}{n+m}+\frac{c_{s} p(n-m-1)}{2}-\frac{c_{h} \lambda p}{2}\right) \frac{T^{2}}{(n+m)} \\
& +\frac{n p}{(n+m)}\left(s-c_{f p}-\lambda c_{p}-\lambda c_{i}-\lambda c_{t 1}\right) T-\frac{n^{2}}{(n+m)}\left(K+c_{t 0}\right) .
\end{aligned}
$$

Theorem 4.1. $\Pi_{m 1}(\tau)$ in equation (4.2) is a strictly pseudo concave function of $\tau$, satisfies the $\quad$ inequality $-\frac{\alpha \lambda p}{(n+m)}\left(n c_{h} \beta-c_{p} i_{e}(\beta+2)\right) \tau^{\beta}-\frac{n \lambda \alpha p}{(n+m)(\beta+1)}\left(c_{p}+c_{i}+c_{t 1}\right) \tau^{\beta-1}-\frac{3 c_{s}(n-m-1) p \nu}{2 n(n+m)} \tau+$ $\frac{p}{(n+m)}\left(c_{p} \lambda i_{e}+\frac{2 s i_{e}^{d} \eta}{(n+m)}+c_{s}(n-m-1)-c_{h} \lambda\right)<0$, for which the function is maximum.

Proof. See the Appendix B.

For the same reason, with the given values of $T$ and $n, \Pi_{m}(T, n)$ becomes a function $n$ alone and let it be $\Pi_{m 3}(n)$, is concave with respect to $n$. The number of delivered of the raw material is a positive integer, a discrete variable; one can find the optimum values of $n$ as $n^{*}$, for which $\frac{\mathrm{d} \Pi_{m 3}(n)}{\mathrm{d} n}=0$ and $n^{*}=$ nearest integer of $\mathrm{n}$ with $\rho=\operatorname{Int}[n]$ such that

$$
\Pi_{m}\left(n^{*}\right)=\operatorname{Max}: \Pi_{m}(\xi) \text {, for all } \xi \in[\rho, \rho+1] .
$$

\section{Solution PROCEDURE}

To solve the objective of the proposed model the iterative heuristic procedure is applied and used the MATHEMATICA 9.0 software.

\section{Algorithm}

Step 1. Input all the parameters associated with the model.

Step 2. Since the number of delivery of raw material as well as the delivery of the finished product to the retailers is discrete variable and integer, we have chosen $n$ as integer and $n \geq 1$.

Step 3. For the choosing value of $\mathrm{n}$, solve the equation for $\tau$ such that $-\frac{\alpha p \lambda}{(n+m)(\beta+1)}\left(n c_{h} \beta-(\beta+2) c_{p} i_{e}\right) \tau^{\beta+1}-$ $\frac{n \alpha p \lambda}{(n+m)}\left(c_{p}+c_{i}+c_{t 1}\right) \tau^{\beta}-\frac{3 c_{s} \nu(n-m-1) p}{4 n(n+m)} \tau^{2}+\left(2 c_{p} \lambda i_{e} p+\frac{2 s i_{e}^{d} p \eta}{n+m}+\frac{c_{s} p(n-m-1)}{2}-c_{h} \lambda p\right) \frac{\tau}{(n+m)}+\frac{n p}{(n+m)}(s-$ $\left.c_{f p}-\lambda c_{p}-\lambda c_{i}-\lambda c_{t 1}\right)=0$. Let it be $\tau^{*}$ and set $\tau^{*}=T^{*}$.

Step 4. If $T^{*}$ satisfies the inequality $\Psi\left(T^{*}\right)=-\frac{\alpha p \lambda}{(n+m)}\left(n c_{h} \beta-(\beta+2) c_{p} i_{e}\right) \tau^{\beta}-\frac{n \alpha p \lambda \beta}{(n+m)}\left(c_{p}+c_{i}+c_{t 1}\right) \tau^{\beta-1}-$ $\frac{3 c_{s} \nu(n-m-1) p}{2 n(n+m)} \tau+\left(2 c_{p} \lambda i_{e}+\frac{2 s i_{e}^{d} \eta}{n+m}+\frac{c_{s}(n-m-1)}{2}-c_{h} \lambda\right) \frac{p}{(n+m)}<0$. Then the optimal solution is $\left(T^{*}, n^{*}\right)$ which maximizes the objective.

Step 5. Repeating Steps $2-4$, the optimal solution $\left(T^{*}, n^{*}\right)$ must satisfy the condition $\Pi_{m}\left(T^{*}\left(n^{*}-1\right), n^{*}-1\right) \leq \Pi_{m}\left(T^{*}\left(n^{*}\right), n^{*}\right) \geq \Pi_{m}\left(T^{*}\left(n^{*}+1\right), n^{*}+1\right)$.

Step 6. End the procedure. 
TABLE 2. Optimum values of $n, T$ and profit per unit time using the said algorithm.

\begin{tabular}{llll}
\hline $\begin{array}{l}\text { Numbers of } \\
\text { deliveries }\left(n^{*}\right)\end{array}$ & $\begin{array}{l}\text { Production } \\
\text { time }\left(T^{*}\right)\end{array}$ & $\Psi\left(T^{*}\right)$ & $\begin{array}{l}\text { Profit per } \\
\text { unit time }\end{array}$ \\
\hline 6 & 1.59387 & -40527.6 & 8758.8 \\
7 & 1.67921 & -44914.7 & 8985.9 \\
8 & 1.75574 & -49039.4 & 9126.2 \\
9 & 1.82539 & -52941.9 & 9202.8 \\
$\mathbf{1 0}$ & $\mathbf{1 . 8 8 9 4 6}$ & $\mathbf{- 5 6 6 7 8 . 8}$ & $\mathbf{9 2 3 1 . 8}$ \\
11 & 1.94892 & -60252.3 & 9224.6 \\
12 & 2.00449 & -63690.4 & 9189.1 \\
13 & 2.05673 & -67000.9 & 9131.6 \\
14 & 2.10608 & -70221.2 & 9056.2 \\
\hline
\end{tabular}

Notes. Bold faces values indicates the optimum results of decision variables and objective function

\section{NumericAl EXAMPLE}

A local brand Tomato souse producer Mitra and Company, at Kharagpur, West Bengal, India, produces the tomato souse and deliver the product to the retailers (in number four), who are selling the product to the customers of Egra Municipality, Purba Medinipur, West Bengal, India. At Midnapore, West Bengal, India, a stockiest Krishna Agro food traders, supply the raw material (Tomato) to the Mitra and Company. From the observation of manager (Mob.No.: +918348017157 and e-mail: satyabratasahoo035@gmail.com) of Mitra and Company, it was found that $10 \mathrm{~kg}$ raw tomato (on average) is required for producing a $5 \mathrm{~kg}$ tomato souse bottle. The data (values of the parameters) of Mitra and Company, related to the proposed model are as follows: $K=$ Rs. 500/order, $p=100$ units/year, $s=$ Rs. 200/product, $i_{e}^{d}=$ Rs. $0.05 /$ year, $m=3 \in Z^{+}$, $i_{e}=$ Rs. $0.05 /$ year, $c_{p}=$ Rs. $5 /$ product, $c_{i}=$ Rs. $1.0 /$ product, $c_{h}=$ Rs. $2.0 /$ product $/$ year, $c_{f p}=$ Rs. $5.0 /$ product, $c_{s}=$ Rs. 1.0/product/year, $c_{t 0}=$ Rs. 10/deliver, $c_{t 1}=$ Rs. 1.0/product/deliver, $\alpha=0.5 \in R^{+}, \beta=2 \in R^{+}$, $\nu=0.1 \in R^{+}$. For simplicity, consider only 4 retailers having input parameters are as follows: $k_{j}=3 \in R^{+}$, $\beta_{j}=0.5 \in R^{+}, \delta_{j}=0.25 \in R^{+}$for $j=1,2,3$, 4. Considering the said search procedure with the algorithm in section 5 , we can find the optimum value $\left(T^{*}, n^{*}\right)$, which maximize the profit per unit time shown in Table 2.

Here, it is observed that, for a given value of $m=3, \Pi_{m}(T, n)$ is the concave function with respect to both the variables $T$ and $n$. The optimum values of $n$ and $T$ are respectively $n^{*}=10$ and $T^{*}=1.88946$. Also, the corresponding optimum profit per unit time is $\Pi_{m}^{*}\left(T^{*}, n^{*}\right)=$ Rs. 9231.8. The optimum values of the other related decision variables are $Q_{s i}^{*}$ for $i=1,2, \ldots, 10$ are respectively as $38,39,42,46,52,58,66,76,87,99$ and the total optimal ordering quantity is $Q^{*}=603$ unit. The total cold storage cost is Rs. 82.28 . The concavity representations of $\Pi_{m}(T, n)$ (profit per unit time) with respect to $n$ and $T$ are shown in Figures 3 and 4 , respectively.

Comparison between $n$ and $m$. For different values of $m$, the optimum values of $T^{*}, n^{*}$ and profit per unit time are shown in Table 3.

From Table 3, it is observed that the increasing value of $m$ causes higher values of $n$ and larger production time. As a result, profit per unit time decreases. So, for maximum profit, the manager of the production cell should avoid large-scale number of delivery after production.

\section{SENSITIVITY ANALYSIS AND DISCUSSION}

In this section, the sensitivity analysis is carried out by changing the different model parameters (changes of one parameter at a time and the remaining parameters unchanged). The changes of optimum profit per unit time $\left(\Pi_{m}(T, n)\right)$, optimum production time $(T)$ and the optimum number of deliveries of raw material $(n)$ are shown in Table 4 and graphically depicted in Figures $5-7$. 
TABLE 3. Maximum profit per unit time for different $m$.

\begin{tabular}{llll}
\hline \hline$m$ & $\begin{array}{l}\text { Numbers of } \\
\text { deliveries }\left(n^{*}\right)\end{array}$ & $\begin{array}{l}\text { Production } \\
\text { time }\left(T^{*}\right)\end{array}$ & $\begin{array}{l}\text { Profit per } \\
\text { unit time }\end{array}$ \\
\hline 1 & 6 & 1.6037 & 11288.0 \\
2 & 8 & 1.7594 & 10049.2 \\
3 & 10 & 1.8895 & 9231.8 \\
4 & 12 & 2.0020 & 8607.3 \\
5 & 13 & 2.0522 & 8103.7 \\
\hline
\end{tabular}

TABLE 4. Results of sensitivity analysis with respect to $p, s, c_{p}, c_{f p}, \lambda, \alpha, \beta, \nu$.

\begin{tabular}{|c|c|c|c|c|}
\hline \multirow[t]{2}{*}{ Parameters } & \multirow{2}{*}{$\begin{array}{l}\% \text { of change } \\
\text { parameters }\end{array}$} & \multicolumn{3}{|c|}{$\%$ change in optimal values } \\
\hline & & $\begin{array}{l}\text { Optimum profit } \\
\text { per unit time } \\
\left(\Pi_{m}(T, n)\right)\end{array}$ & $\begin{array}{l}\text { Optimum prod- } \\
\text { uction time } \\
(T)\end{array}$ & $\begin{array}{l}\text { Optimum number } \\
\text { of deliveries } \\
(n)\end{array}$ \\
\hline \multirow{4}{*}{$p$} & -40 & -48 & +09 & -20 \\
\hline & -20 & -24 & +04 & -10 \\
\hline & +20 & +25 & -03 & +10 \\
\hline & +40 & +50 & -05 & +20 \\
\hline \multirow{4}{*}{$s$} & -40 & -63 & -16 & -40 \\
\hline & -20 & -33 & -07 & -20 \\
\hline & +20 & +34 & +06 & +20 \\
\hline & +40 & +70 & +12 & +40 \\
\hline \multirow{4}{*}{$c_{p}$} & -40 & +05 & +09 & +10 \\
\hline & -20 & +02 & +06 & +10 \\
\hline & +20 & -02 & -02 & No changed \\
\hline & +40 & -05 & -04 & No changed \\
\hline \multirow{4}{*}{$c_{f p}$} & -40 & +02 & No changed & No changed \\
\hline & -20 & +01 & No changed & No changed \\
\hline & +20 & -01 & No changed & No changed \\
\hline & +40 & -02 & No changed & No changed \\
\hline \multirow{4}{*}{$\lambda$} & -40 & +09 & +21 & +20 \\
\hline & -20 & +04 & +09 & +10 \\
\hline & +20 & -04 & -05 & No changed \\
\hline & +40 & -08 & -12 & -10 \\
\hline \multirow{4}{*}{$\alpha$} & -40 & +04 & +18 & +10 \\
\hline & -20 & +02 & +09 & +10 \\
\hline & +20 & -02 & -05 & No changed \\
\hline & +40 & -03 & -09 & No changed \\
\hline \multirow{4}{*}{$\beta$} & -40 & +04 & +39 & +20 \\
\hline & -20 & +02 & +15 & +10 \\
\hline & +20 & -01 & -08 & No changed \\
\hline & +40 & -02 & -16 & -10 \\
\hline \multirow{4}{*}{$\nu$} & -40 & -11 & No changed & No changed \\
\hline & -20 & -04 & No changed & No changed \\
\hline & +20 & +03 & No changed & No changed \\
\hline & +40 & +05 & No changed & +10 \\
\hline
\end{tabular}




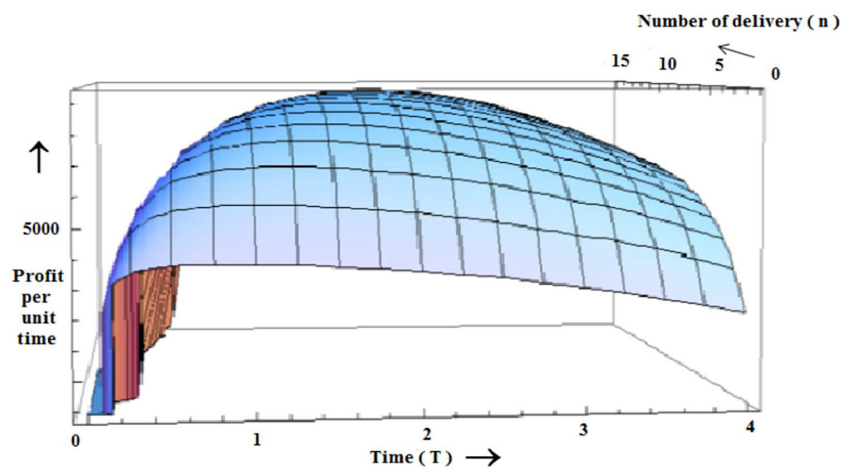

FiguRE 3. Concavity of $\Pi_{m}(T, n)$ with respect to $n$ and $T$.
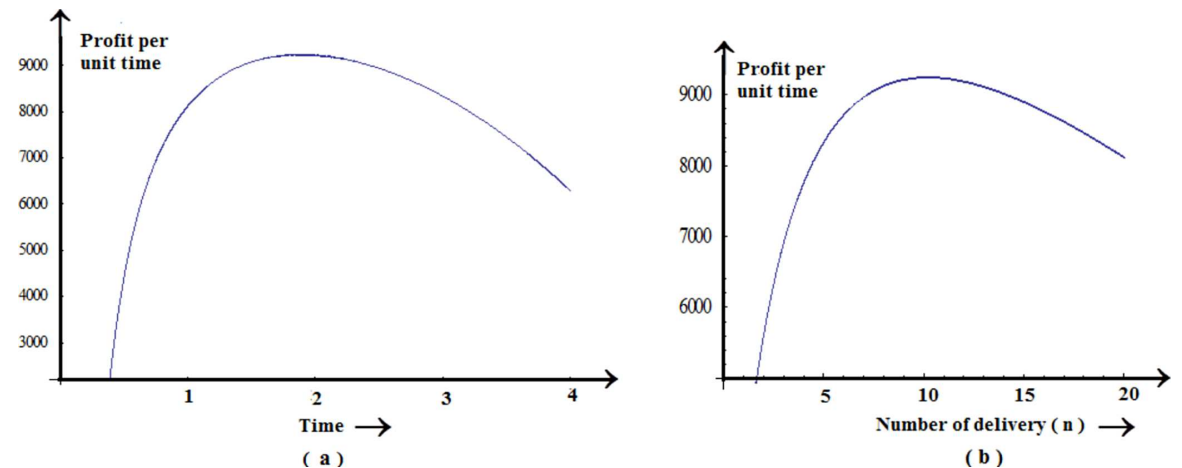

FiguRE 4. Concavity of $\Pi_{m}(T, n)$ (a) with respect to $T$ and (b) with respect to $n$.

From Table 4, it is observed that:

(i) the optimum profit per unit time of the food producer increases or decreases mainly due to the increase or decrease of the selling price $(s)$ and preservation rate $(p)$ of the product. Also, it is increases or decreases slightly with the decrease or increase of unit raw material purchase cost $\left(c_{p}\right)$, unit food preparation cost $\left(c_{f p}\right), \lambda, \alpha$ and $\beta$. Moreover, the food producer's optimum profit per unit time increases or decreases slightly due to the decrease or increase of $\nu$.

(ii) The optimum production time of the food producer increases or decreases moderately due to the increase or decrease of the selling price $(s)$ of the product. Again, it is increases or decreases moderately with the decrease or increase of $\lambda, \alpha$ and $\beta$. Also, the optimum production time of the food producer increases or decreases slightly due to the decrease or increase of $p, c_{p}$, whereas it is not changing due to the increase or decrease of $c_{f p}, \nu$.

(iii) The optimum number of deliveries increases or decreases moderately and equally due to the increase or decrease of $p$ and $s$, respectively. Also, it is either partially or not changes due to the increase or decrease of $c_{p}, c_{f p}, \nu, \lambda, \alpha$ and $\beta$.

From Figures $5-7$, it is observed that

(i) $\Pi_{m}(T, n)$ (food producer's profit per unit time) is highly sensitive directly with the changes of $s$ and $p$, whereas it is less sensitive reversely with respect to $c_{p}, c_{f p}, \lambda, \alpha$ and $\beta$. On the other hand, $\Pi_{m}(T, n)$ slightly reverse sensitive with respect to $\nu$. 


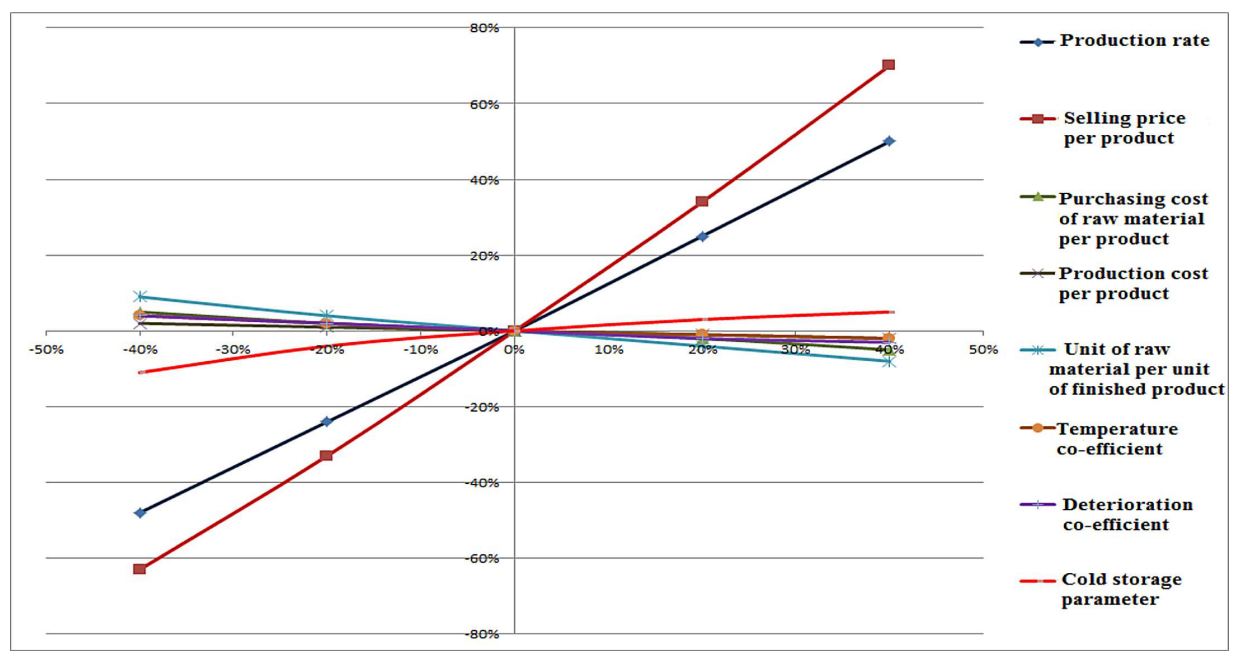

FiguRE 5. Effects of $\Pi_{m}(T, n)$ with different percentage changes of $p, s, c_{p}, c_{f p}, \lambda, \alpha, \beta, \nu$.

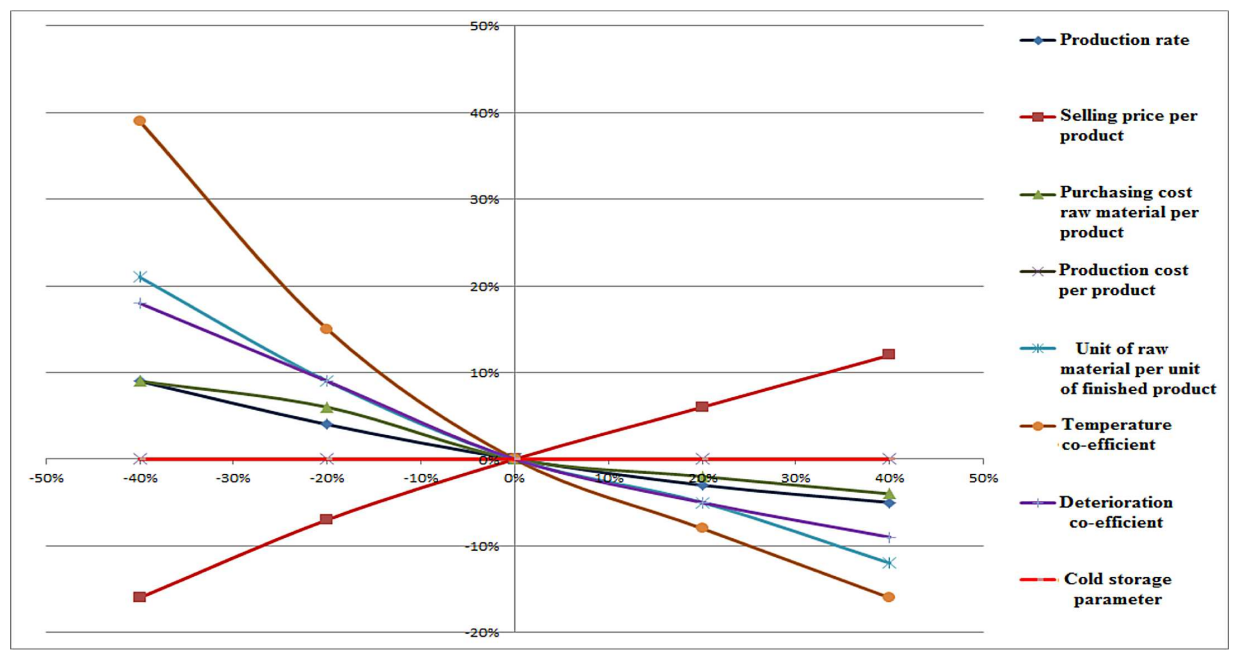

FiguRE 6. Effects of $T$ with different percentage changes of $p, s, c_{p}, c_{f p}, \lambda, \alpha, \beta, \nu$.

(ii) $T$ (food producer's production time) is moderately sensitive directly with respect to $s$, whereas it is moderately reverse sensitive with respect to $\lambda, \alpha$ and $\beta$. Also, $T$ is less sensitive reversely with changes of $p, c_{p}$ and insensitive with respect to $c_{f p}, \nu$.

(iii) $n$ (number of deliveries of retailer's order) is moderately and equally sensitive with respect to $p$ and $s$, respectively. Also, it is less sensitive reversely with respect to $c_{p}, c_{f p}, \nu, \lambda, \alpha$ and $\beta$.

Therefore, from Table 4 and Figures $5-7$, the following observations are found:

(i) If food producer's preservation rate $(p)$ increases, then food producer's production time $(T)$ decreases; as a result, a lot of the finished product is more significant and increases the food producer's profit per unit time. Simultaneously, to avoid a considerable amount of deterioration of raw materials, the number of delivery of raw materials should be increased. 


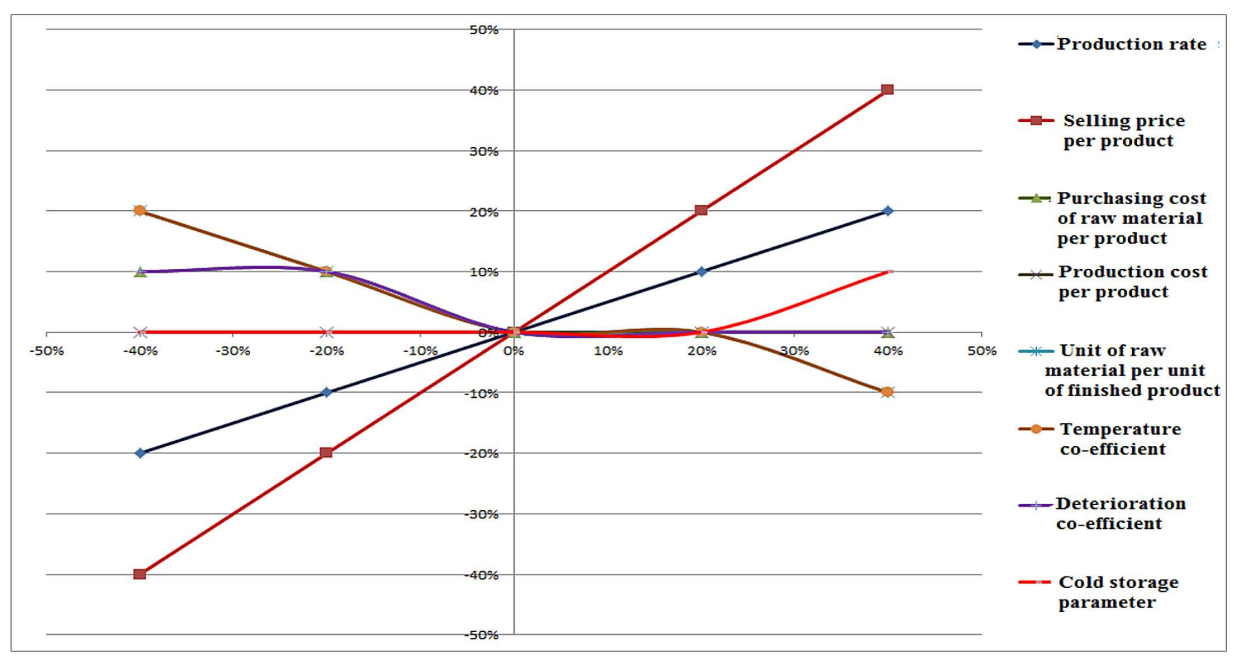

FiguRE 7. Effects of $n$ with different percentage changes of $p, s, c_{p}, c_{f p}, \lambda, \alpha, \beta, \nu$.

(ii) If the number of delivery of raw material $(n)$ increases, then $T$ increase; as a result, food producer get more profit.

\section{MANAGERIAL INSIGHTS}

The food processing and its preservation industry in any developing country are increasingly seen as a potential source for driving the rural economy as it brings about the synergy between the consumer, industry and the farmer. The demand for processed, packed and convenient food with prolonged shelf life requires welltrained human resource in the food industry. There is an encouraging, challenging and rewarding future for professions and careers in the food technology and the food processing industry. As this field requires the application of science and technology to the processing, utilisation, preservation, packaging and distribution of food and food products, it encompasses a diverse range of specialisations. The proposed model is applicable for the short lifecycle deteriorating products. Using the model, managers of such products can decide optimum investment in preservation technology, plan the schedule of production and inventory more precisely, which helps clean the production system by avoiding/reducing deterioration of the products. This work gives a brief idea about the importance of investment in preservation, advance and delayed payments policies in the food supply chain model. Also, we have addressed cold storage cost, which is dependent on cold storage space and power consumption. Moreover, we have proposed the deterioration rate before preservation is dependent on environmental factors and temperature. So, this model can be implicated significantly in a particular types of deteriorating food production industry such as fruit juice, lassi factories etc. Based on this study, we have drawn the following managerial insights: (i) the preservation investment for deteriorating goods significantly impacts both environment and food producer's average profit. (ii) For the maximum profit of the food producer should avoid a long number of delivery of the finished product to the retailers. (iii) Also, due to the cause of deterioration of the raw material depends on environmental factors and temperature with time, the production rate of the raw material should be higher.

\section{Conclusions AND Future Research}

This paper presented a food preservation supply chain model of a deteriorating item under upstream delayin-payment and down-stream pre-payment. In the proposed model, the food producer demands to the retailers 
to pay a part of the purchase cost of an order by several equal-amount payments at a fixed time interval before the delivery of goods. Also, the supplier offers to the food producer a delay-in-payment of the entire purchase cost of an order. As a result, food producer gets joint benefit from delayed payment as well as advance payment. It is observed that the proposed advance and trade credit scheme has increased the merit of this supply chain model, whereas deterioration of the item is a crucial factor in the food supply chain system and especially for the food producer. Here, it is assumed that the deterioration rate is dependent on environmental factors and temperature. From this study, it is concluded that cold storage facility reduces the deterioration and it controls the quality of the produced food. Concavity of the average profit function is derived analytically and graphically as well as the optimal solution is obtained. Finally, sensitivity analysis, along with graphical illustrations on the key parameters of the model, is provided to test the feasibility of the model. From the sensitivity analysis, it is concluded that the deterioration rate of the raw material increases when the production time of food producer decreases and as a result, the profit per unit time of the food producer decreases.

In the future, this work can be extended by considering greenhouse gas (GHG) emissions during food preservation in cold storage, transportation, temperature controlled area etc. Again, this model may be extended by considering the imprecise model parameters regarding deterioration, demand and different costs related to the model.

\section{Appendix A.}

Let $\mathrm{H}$ be the Hessian matrix of the objective function $\Pi_{m}(T, n)$. For concavity of the function, the sufficient condition that $\frac{\partial^{2} \Pi_{m}(T, n)}{\partial T^{2}}<0, \frac{\partial^{2} \Pi_{m}(T, n)}{\partial n^{2}}<0$ and the determinant value of Hessian matrix must be positive. That is, $|H|=\frac{\partial^{2} \Pi_{m}(T, n)}{\partial T^{2}} \times \frac{\partial^{2} \Pi_{m}(T, n)}{\partial n^{2}}-\left(\frac{\partial^{2} \Pi_{m}(T, n)}{\partial T \partial n}\right)^{2}>0$.

Theoretically, the evaluation of these second order derivatives and the determinant value of the Hessian matrix are too complicated. So, the property of concavity can be proved numerically. Using MATHEMATICA software, with the same input data of numerical example, the value of $T$ and $n$ are $T^{*}=1.88946$ and $n^{*}=10$, which satisfies the equations $\frac{\partial \Pi_{m}(T, n)}{\partial T}=0$ and $\frac{\partial \Pi_{m}(T, n)}{\partial n}=0$ simultaneously.

$$
\begin{aligned}
& \operatorname{Now}\left[\frac{\partial^{2} \Pi_{m}(T, n)}{\partial T^{2}}\right]_{(T=1.88946, n=10)}=-1821.51<0,\left[\frac{\partial^{2} \Pi_{m}(T, n)}{\partial n^{2}}\right]_{(T=1.88946, n=10)}=-42.97<0 \text { and } \\
& {\left[\frac{\partial^{2} \Pi_{m}(T, n)}{\partial T \partial n}\right]_{(T=1.88946, n=10)}=112.26>0 .}
\end{aligned}
$$

It follows that $|H|=\frac{\partial^{2} \Pi_{m}(T, n)}{\partial T^{2}} \times \frac{\partial^{2} \Pi_{m}(T, n)}{\partial n^{2}}-\left(\frac{\partial^{2} \Pi_{m}(T, n)}{\partial T \partial n}\right)^{2}=65678.5>0$. Hence, the solution is a unique optimal solution, which maximizes the objective function $\Pi_{m}(T, n)$.

\section{Appendix B.}

Proof of the Theorem 4.1. From the equation (4.2), we get

$$
\begin{aligned}
\Pi_{m 1}(\tau)= & \frac{\alpha p \lambda}{(n+m)(\beta+1)}\left(c_{p} i_{e}-\frac{n \beta c_{h}}{\beta+2}\right) \tau^{\beta+2}-\frac{n \alpha p \lambda}{(n+m)(\beta+1)}\left(c_{p}+c_{i}+c_{t 1}\right) \tau^{\beta+1} \\
& -\frac{c_{s} \nu(n-m-1) p}{4 n(n+m)} \tau^{3}+\left(c_{p} \lambda i_{e} p+\frac{s i_{e}^{d} p \eta}{n+m}+\frac{c_{s} p(n-m-1)}{2}-\frac{c_{h} \lambda p}{2}\right) \frac{\tau^{2}}{(n+m)} \\
& +\frac{n p}{(n+m)}\left(s-c_{f p}-\lambda c_{p}-\lambda c_{i}-\lambda c_{t 1}\right) \tau-\frac{n^{2}}{(n+m)}\left(K+c_{t 0}\right) .
\end{aligned}
$$

The 1st and 2nd order derivatives of it becomes

$$
\frac{\mathrm{d} \Pi_{m 1}(\tau)}{\mathrm{d} \tau}=-\frac{\alpha p \lambda}{(n+m)(\beta+1)}\left(n c_{h} \beta-(\beta+2) c_{p} i_{e}\right) \tau^{\beta+1}-\frac{n \alpha p \lambda}{(n+m)}\left(c_{p}+c_{i}+c_{t 1}\right) \tau^{\beta}
$$




$$
\begin{aligned}
& -\frac{3 c_{s} \nu(n-m-1) p}{4 n(n+m)} \tau^{2}+\left(2 c_{p} \lambda i_{e} p+\frac{2 s i_{e}^{d} p \eta}{n+m}+\frac{c_{s} p(n-m-1)}{2}-c_{h} \lambda p\right) \frac{\tau}{(n+m)} \\
& +\frac{n p}{(n+m)}\left(s-c_{f p}-\lambda c_{p}-\lambda c_{i}-\lambda c_{t 1}\right) \\
\text { and } \frac{\mathrm{d}^{2} \Pi_{m 1}(\tau)}{\mathrm{d} \tau^{2}}= & -\frac{\alpha p \lambda}{(n+m)}\left(n c_{h} \beta-(\beta+2) c_{p} i_{e}\right) \tau^{\beta}-\frac{p\left(3 c_{s}(n-m-1) \nu \tau+2 n c_{h} \lambda-4 n c_{p} \lambda i_{e}\right)}{2 n(n+m)} \\
& -\frac{n \alpha p \lambda \beta}{(n+m)}\left(c_{p}+c_{i}+c_{t 1}\right) \tau^{\beta-1}+\left(\frac{2 s i_{e}^{d} \eta}{n+m}+\frac{c_{s}(n-m-1)}{2}\right) \frac{p}{(n+m)} .
\end{aligned}
$$

Let $\tau^{*}$ be the solution of $\frac{\mathrm{d} \Pi_{m 1}(\tau)}{\mathrm{d} \tau}=0$ and it satisfies the inequality $-\frac{\alpha p \lambda}{(n+m)}\left(n c_{h} \beta-(\beta+2) c_{p} i_{e}\right)\left(\tau^{*}\right)^{\beta}-$ $\frac{n \alpha p \lambda \beta}{(n+m)}\left(c_{p}+c_{i}+c_{t 1}\right)\left(\tau^{*}\right)^{\beta-1}-\frac{3 c_{s} \nu(n-m-1) p}{2 n(n+m)} \tau^{*}+\left(2 c_{p} \lambda i_{e}+\frac{2 s i_{e}^{d} \eta}{n+m}+\frac{c_{s}(n-m-1)}{2}-c_{h} \lambda\right) \frac{p}{(n+m)}<0$ for all $\tau^{*} \in$ $(0, \infty)$. Then considering the results of Cambibi and Martein [3], the function $\Pi_{m}(\tau, n)=\frac{\Pi_{m 1}(\tau)}{\Pi_{m 2}(\tau)}$, where $\Pi_{m 2}(\tau)=\tau>0$ for all $\tau \in(0, \infty)$, and for all $\tau, \frac{\mathrm{d} \Pi_{m 2}(\tau)}{\mathrm{d} \tau}=1>0$. Therefore, it is strictly pseudo concave with respect to $\tau$. It follows that there exists a unique global value of $\tau$ which maximizes $\Pi_{m}(\tau, n)$. Hence the theorem is proved.

Acknowledgements. The authors express their sincere thanks to the editor and the anonymous reviewers for their valuable and constructive comments and suggestions leading to a significant improvement of the manuscript.

\section{REFERENCES}

[1] A.K. Bhunia and M. Maiti, An inventory model of deteriorating items with lot-size dependent replenishment cost and linear trend in demand. Appl. Math. Model. 23 (1999) 301-308.

[2] A.K. Bhunia and A.A. Shaikh, An application of PSO in a two-warehouse inventory model for deteriorating item under permissible delay in payment with different inventory policies. Appl. Math. Comput. 256 (2015) 831-850.

[3] A. Cambibi and L. Martein, Generalized Convexity and Optimization: Theory and Applications. Lecture Notes in Economics and Mathematical Systems. Vol. 616. Springer (2009).

[4] Y.-R. Chen and C.-Y. Dye, Application of particle swarm optimization for solving deteriorating inventory model with fluctuating demand and controllable deterioration rate. Int. J. Syst. Sci. 44 (2013) 1026-1039.

[5] L.-H. Chen and F.-S. Kang, Integrated inventory models considering the two-level trade credit policy and a price-negotiation scheme. Eur. J. Oper. Res. 205 (2010) 47-58.

[6] M.G. Corradini and M. Peleg, Prediction of vitamins loss during non-isothermal heat processes and storage with non-linear kinetic models. Trends Food Sci. Technol. 17 (2006) 24-34.

[7] S.C. Das, A.K. Manna, M.S. Rahman, A.A. Shaikh and A.K. Bhunia, An inventory model for non-instantaneous deteriorating items with preservation technology and multiple credit periods-based trade credit financing via particle swarm optimization. Soft Comput. 25 (2021) 5365-5384.

[8] A. Diabat, A.A. Taleizadeh and M. Lashgari, A lot sizing model with partial downstream delayed payment, partial upstream advance payment, and partial back ordering for deteriorating items. J. Manuf. Syst. 45 (2017) 322-342.

[9] C.-Y. Dye, The effect of preservation technology investment on a non-instantaneous deteriorating inventory model. OMEGA Int. J. Manage. Sci. 41 (2013) 872-880.

[10] C.-Y. Dye and T.-P. Hsieh, An optimal replenishment policy for deteriorating items with effective investment in preservation technology. Eur. J. Oper. Res. 218 (2012) 106-112.

[11] M.E. Ferguson and M.E. Ketzenberg, Information Sharing to Improve Retail Product Freshness of Perishables, 3rd edition. Georgia Institute of Technology (2005).

[12] P.K. Ghosh, A.K. Manna, J.K. Dey and S. Kar, Supply chain coordination model for green product with different payment strategies: a game theoretic approach. J. Cleaner Prod. 290 (2021) 125734.

[13] P.K. Ghosh, A.K. Manna, J.K. Dey and S. Kar, An EOQ model with backordering for perishable product under multiple advanced and delayed payments policies. J. Manage. Anal. (2021) 1-12. DOI: 10.1080/23270012.2021.1882348.

[14] S.K. Goyal, Economic order quantity under the condition of permissible delay in payments. J. Oper. Res. Soc. 36 (1985) $335-338$.

[15] M. Gupta, S. Tiwari and C.K. Jaggi, Retailer's ordering policies for time-varying deteriorating items with partial backlogging and permissible delay in payments in a two-warehouse environment. Ann. Oper. Res. 295 (2020) 139-161.

[16] F.W. Harris, How many parts to make at once, Factory. Mag. Manage. 10 (1913) 135-136.

[17] Y. He and Y. Huang, Optimizing inventory and pricing policy for seasonal deteriorating products with preservation technology investment. J. Ind. Eng. 2013 (2013) 1-7. 
[18] M.A.A. Khan, A.A. Shaikh, G.C. Panda and I. Konstantaras, Two-warehouse inventory model for deteriorating items with partial backlogging and advance payment scheme. RAIRO-Oper. Res. 53 (2019) 1691-1708.

[19] R. Li, Y.-L. Chan, C.-T. Chang and L.E. Cárdenas-Barrón, Pricing and lot-sizing policies for perishable products with advancecash-credit payments by a discounted cash flow analysis. Int. J. Prod. Econ. 193 (2017) 578-589.

[20] G.C. Mahata, An EPQ-based inventory model for exponentially deteriorating items under retailer partial trade credit policy in supply chain. Expert Syst. App. 39 (2012) 3537-3550.

[21] A.K. Manna, J.K. Dey and S.K. Mondal, Effect of inspection errors on imperfect production inventory model with warranty and price discount dependent demand rate. RAIRO-Oper. Res. 54 (2020) 1189-1213.

[22] R. Martin, China must improve its cool supply chain to keep pace with demand for fresh food. http://theloadstar.co.uk/ coolstar/china-mustimprove-its-cool-supply-chain-to-keep-pace-with-demand-for-fresh-food (2015).

[23] G.D. Orris and A.J. Whitehead, Hazard analysis and critical control point (HACCP) as a part of an overall quality assurance system in international food trade. Food Control 11 (2000) 345-351.

[24] Y. Qin, J. Wang and C. Wei, Joint pricing and inventory control for fresh produce and foods with quality and physical quantity deteriorating simultaneously. Int. J. Prod. Econ. 152 (2014) 42-48.

[25] H. Ronald, G. Schmidt and E. Rodrick, Definition of food safety. In: Food Safety Handbook. Wilely-IEEE3-7 (2005).

[26] N.H. Shah, M.Y. Jani and U. Chaudhari, Optimal replenishment time for retailer under partial upstream prepayment and partial downstream overdue payment for quadratic demand. Math. Comput. Model. Dyn. Syst. 24 (2017) 1-11.

[27] K. Skouri and S. Papachristos, A continuous review inventory model with deteriorating items time varying demand linear replenishment cost partially time varyingbacklogging. Appl. Math. Model. 26 (2002) 603-617.

[28] K. Skouri, I. Konstantaras, S. Papachristos and I. Ganas, Inventory models with ramp type demand rate, partial backlogging and Weibull deterioration rate. Eur. J. Oper. Res. 192 (2009) 79-92.

[29] D. Smith, Design and management concepts for high care food processing. Br. Food J. 108 (2006) 54-60.

[30] A.A. Taleizadeh, D.W. Pentico, M.S. Jabalameli and M. Aryanezhad, An economic order quantity model with multiple partial prepayments and partial backordering. Math. Comput. Model. 57 (2013) 311-323.

[31] A.A. Taleizadeh, An economic order quantity model for deteriorating items in a purchasing system with multiple prepayments. Appl. Math. Model. 38 (2014) 5357-5366.

[32] J.T. Teng, J. Min and Q. Pan, Economic order quantity model with trade credit financing for non-decreasing demand. Omega 40 (2012) 328-335.

[33] J.T. Teng, L.E. Cárdenas-Barrón, H.J. Chang, J. Wu and Y. Hu, Inventory lot-size policies for deteriorating items with expiration dates and advance payments. Appl. Math. Model. 40 (2016) 8605-8616.

[34] A. Thangam and R. Uthayakumar, Two-echelon trade credit financing for perishable items in a supply chain when demand depends on both selling price and credit period. Comput. Ind. Eng. 57 (2009) 773-786.

[35] S. Tiwari, L.E. Cárdenas-Barrón, M. Goh and A.A. Shaikh, Joint pricing and inventory model for deteriorating items with expiration dates and partial backlogging under two-level partial trade credits in supply chain. Int. J. Prod. Econ. 200 (2018) $16-36$.

[36] Y.-C. Tsao, A piecewise nonlinear optimization for a production-inventory model under maintenance, variable setup costs, and trade credits. Ann. Oper. Res. 233 (2015) 465-481.

[37] M.-F. Yang and W.-C. Tseng, Deteriorating inventory model for chilled food. Math. Prob. Eng. 2015 (2015) 1-10.

[38] A.X. Zhang, Optimal advance payment scheme involving fixed per-payment costs. Omega 24 (1996) 577-582.

\section{Subscribe to Open (S2O) A fair and sustainable open access model}

This journal is currently published in open access under a Subscribe-to-Open model (S2O). S2O is a transformative model that aims to move subscription journals to open access. Open access is the free, immediate, online availability of research articles combined with the rights to use these articles fully in the digital environment. We are thankful to our subscribers and sponsors for making it possible to publish this journal in open access, free of charge for authors.

\section{Please help to maintain this journal in open access!}

Check that your library subscribes to the journal, or make a personal donation to the S2O programme, by contacting subscribers@edpsciences.org

More information, including a list of sponsors and a financial transparency report, available at: https://www. edpsciences.org/en/maths-s2o-programme 